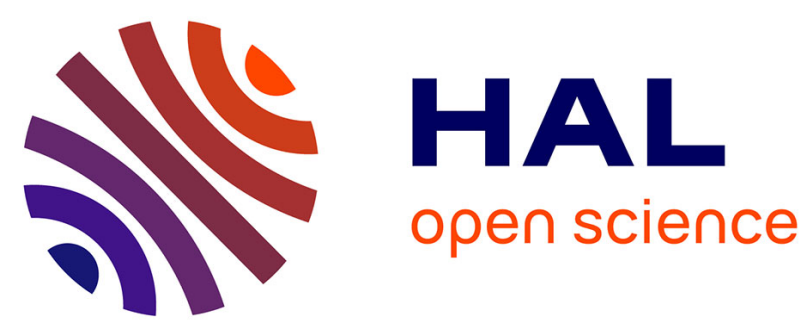

\title{
Increased functional connectivity between language and visually deprived areas in late and partial blindness
}

Norman Sabbah, Colas N. Authié, Nicolae Sanda, Saddek Mohand-Saïd, José-Alain Sahel, Avinoam B. Safran, Christophe Habas, Amir Amedi

\section{- To cite this version:}

Norman Sabbah, Colas N. Authié, Nicolae Sanda, Saddek Mohand-Saïd, José-Alain Sahel, et al.. Increased functional connectivity between language and visually deprived areas in late and partial blindness. NeuroImage, 2016, 10.1016/j.neuroimage.2016.04.056 . hal-01318038

\section{HAL Id: hal-01318038 \\ https: / hal.sorbonne-universite.fr/hal-01318038}

Submitted on 19 May 2016

HAL is a multi-disciplinary open access archive for the deposit and dissemination of scientific research documents, whether they are published or not. The documents may come from teaching and research institutions in France or abroad, or from public or private research centers.
L'archive ouverte pluridisciplinaire HAL, est destinée au dépôt et à la diffusion de documents scientifiques de niveau recherche, publiés ou non, émanant des établissements d'enseignement et de recherche français ou étrangers, des laboratoires publics ou privés. 


\section{Title}

Increased functional connectivity between language and visually deprived areas in late and partial blindness

\section{Authors}

Norman Sabbah, ${ }^{1-4}$ Colas N. Authié, ${ }^{1-4}$ Nicolae Sanda, ${ }^{1-4}$ Saddek Mohand-Saïd, ${ }^{1-4}$ José-Alain Sahel, ${ }^{1-4,6-7}$ Avinoam B. Safran, ${ }^{1-4,8}$ Christophe Habas, ${ }^{1-3,5}$ Amir Amedi ${ }^{1-3,9-11}$

\section{Affiliations}

${ }^{1}$ Sorbonne Universités, UPMC Université Paris 06, UMR S968, Institut de la Vision, Paris, F75012, France

${ }^{2}$ INSERM, U968, Institut de la Vision, Paris, F-75012, France

${ }^{3}$ CNRS, UMR 7210, Institut de la Vision, Paris, F-75012, France

${ }^{4}$ Centre d'investigation clinique, Centre Hospitalier National d'Ophtalmologie des QuinzeVingts, INSERM-DHOS CIC 1423, Paris, F-75012, France

${ }^{5}$ Centre de neuroimagerie, Centre Hospitalier National d'Ophtalmologie des Quinze-Vingts, Paris, F-75012, France

${ }^{6}$ Institute of Ophthalmology, University College of London, United Kingdom

${ }^{7}$ Fondation Ophtalmologique Adolphe de Rothschild, Paris, France 
${ }^{8}$ Department of Clinical Neurosciences, Geneva University School of Medicine, Geneva, Switzerland

${ }^{9}$ Department of Medical Neurobiology, The Institute for Medical Research Israel-Canada, Faculty of Medicine, The Hebrew University of Jerusalem, Jerusalem 91220, Israel.

${ }^{10}$ The Edmond and Lily Safra Center for Brain Sciences (ELSC), The Hebrew University of Jerusalem, Jerusalem 91220, Israel.

${ }^{11}$ The Cognitive Science Program, The Hebrew University of Jerusalem, Jerusalem 91220, Israel.

\section{Corresponding author}

Norman SABBAH

Institut de la vision, UMR S968

17 rue Moreau 75012 ,

Paris, France

E-mail: norman.sabbah@gmail.com

and

Pr. Amir Amedi

Department of Medical Neurobiology,

Faculty of Medicine, 
The Hebrew University of Jerusalem,

Jerusalem 91220, Israel

E-mail: amira@ekmd.huji.ac.il

Running title

Late visual loss affects language-visual FC

\section{Abstract}

In the congenitally blind, language processing involves visual areas. In the case of normal visual development however, it remains unclear whether later visual loss induces interactions between the language and visual areas. This study compared the resting-state functional connectivity (FC) of retinotopic and language areas in two unique groups of late visually deprived subjects: (1) blind individuals suffering from retinitis pigmentosa (RP), (2) RP subjects without a visual periphery but with preserved central "tunnel vision", both of whom were contrasted with sighted controls. The results showed increased FC between Broca's area and the visually deprived areas in the peripheral $\mathrm{V} 1$ for individuals with tunnel vision, and both the peripheral and central V1 for blind individuals. These findings suggest that FC can develop in the adult brain between the visual and language systems in the completely and partially blind. These changes start in the deprived areas and increase in size (involving both foveal and peripheral V1) 
and strength (from negative to positive $\mathrm{FC}$ ) as the disease and sensory deprivation progress. These observations support the claim that functional connectivity between remote systems that perform completely different tasks can change in the adult brain in cases of total and even partial visual deprivation.

Keywords

Adult brain plasticity, critical periods, Cerebral reorganization, resting-state fMRI, retinitis pigmentosa, brain connectivity, Language \& Vision

\section{Abbreviations}

FC: functional connectivity

RP: retinitis pigmentosa

fMRI: functional magnetic resonance imaging

rs-fMRI: resting-state functional magnetic resonance imaging 


\section{Introduction}

Functional magnetic resonance imaging studies have shown that the relationship between the language and visual areas varies depending on the presence or absence of visual function. For instance, during an abstract word recall task, sighted individuals exhibited strong visual areas deactivation alongside activation of language specific regions (Azulay et al., 2009). In congenitally blind subjects, however, most groups have reported strong activation of the early visual cortex in addition to the classical language areas (e.g. Broca's area) during both verbal memory (Amedi et al., 2003; Azulay et al., 2009) and language-related verb generation tasks (Amedi et al., 2003; Burton et al., 2003, 2002a). Activations of visual areas also play a functional role in both semantic memory and generation tasks, in that blind individuals showing strong recruitment of $\mathrm{V} 1$ also demonstrated superior performance in such processes (Amedi et al., 2003; Raz et al., 2005). Furthermore, language-related early visual cortex activity was shown to make a key contribution to this task in congenitally blind but not in sighted individuals. This is one of the very few examples of a causal relationship indicative of cross-modal plasticity in the blind (Amedi et al., 2004). Bedny et al.'s recent study using a variety of well-controlled language tasks showed that activity in the visual (essentially left) areas actually reflected complex language processing in the congenitally blind. They suggested that there was a critical period for this recruitment, as no such activation was found in the late blind (Bedny et al., 2012, 2011). Anatomically, the semantic processing of the occipital cortex is likely supported by the inferior frontal-occipital fasciculus (IFOF), namely its superficial layer and the posterior component of the deep layer (Sarrubo et al., 2013). Congenitally but not late blind individuals exhibit altered IFOF, decreased structural global connectivity efficiency and increased local connectivity efficiency both in occipital and 
frontal lobes (Liu et al., 2013; Shu et al., 2009; Reislev et al., 2016). These structural changes, together with the above mentioned functional and behavioral data point to early absence of visual input altering brain structure to serve specific tuned-up non-visual functions of occipital cortex. Do only congenitally blind individuals develop this type of early visual cortex recruitment for language and memory? Or can it also occur in the late blind? This issue goes beyond the field of blindness to the wider question of whether this processing can only occur during critical or sensitive periods in childhood or whether some traces and mechanisms for this ability are present even in the adult brain (Bavelier and Neville, 2002; Bedny et al., 2012; Sadato et al., 2002). This has implications for rehabilitation, especially in the context of stroke since the loss of a specialized area requires another area to take over the missing function (Pascual-Leone et al., 2005). It also remains unclear whether visual deprivation needs to be complete for such plasticity to emerge or whether some changes can start even in the presence of residual vision (Cunningham et al., 2015). Finally, little is known about the large-scale anatomical and functional changes that might support such radical brain plasticity.

The current literature provides somewhat conflicting observations on these questions. Burton et al. (2002) found that when listening to words, both congenitally and late blind subjects exhibited bilateral activation of the visual cortex regions in addition to language and auditory areas (Burton et al., 2002a). By contrast, Bedny et al. 2012 found that only the congenitally blind - and not the late blind - showed an increased response in V1 to heard sentences as compared to backwards speech. They concluded that recruitment of the visual cortex for language processing depends critically on the age of blindness onset (Bedny et al., 2012). Thus, even in very recent research it remains unclear whether visual cortex activation by language is affected by previous visual experience in the blind. The picture in the effect of partial blindness on adult brain plasticity and visual input is even more limited and debated. 
The analysis of resting-state functional connectivity constitutes a rich, efficient approach to studying brain function, brain large-scale connectivity and brain plasticity (Fox and Greicius, 2010; Guerra-Carrillo et al., 2014; Smith et al., 2009) as illustrated in the human connectome project (Hodge et al., 2015). These temporal correlations were shown to echo the coactivation between brain regions found in task-based fMRI studies (Buckner et al., 2013; Dosenbach et al., 2007). Of course like any method, rs-fMRI also has some limitations, which are discussed in depth in the discussion (see 4.6. Limitations and methodological considerations). Nevertheless, rs-fMRI is sensitive enough to detect interactions between specific language regions such as Broca's area and the visual cortex. Several teams found specific increased functional connectivity between the inferior frontal triangular gyrus (part of BA 44, 45, 47) including Broca's area and several occipital visual areas in the congenitally blind as compared to sighted subjects (Liu et al., 2007; Heine et al., 2015). Striem-Amit et al. (2015) recently studied the same type of population and found that central V1 was more tightly connected to language areas whereas peripheral V1 was linked to spatial attention and control networks in the congenitally blind as compared to a sighted group (Striem-Amit et al., 2015). Butt et al. (2013) also analyzed the brain resting-state in a heterogeneous population of blind subjects, and suggested that long-range FC between Broca's area and V1 could be explained by age at blindness onset; however, variability in visual conditions (e.g. age onset of vision loss, cause of the disease, visual field location of the scotoma before blindness) combined with the limited number of subjects in each condition constrained data interpretation (Butt et al., 2013). The type of condition has also been considered by other authors (Bedny et al., 2012; Watkins et al., 2012), who have argued that retina versus optic nerve disorders or gradual versus sudden loss of vision may differentially affect the reorganization of the visual cortex. 
Hence, analyzing the functional resting-state connectivity in visually affected individuals categorized into clinically well-defined homogeneous groups in terms of the etiology of blindness might provide valuable indications whether partial or total late deprivation of vision affects the functional links between Broca's area and the visual cortex. The current work was conducted with clinically homogeneous groups of subjects suffering from retinitis pigmentosa, a retinal degenerative condition that causes particularly structured defects initially involving the visual field periphery (and sparing the central "tunnel vision" area), and eventually leading to complete blindness.

Beyond its theoretical contribution, this study has important clinical implications. Late blind patients suffering from RP are the group most expected to benefit from visual restoration such as retinal prosthesis (Ayton et al., 2014; Stingl et al., 2013; Weiland and Humayun, 2014). The existence of cross-modality plasticity mechanisms in RP subjects has only been investigated in a few studies (Cunningham et al., 2015; Masuda et al., 2010) using other methodologies that the ones employed here. Given that there is some evidence of maladaptive cross-modal plasticity in deaf patients following cochlear implantation (Lee et al., 2001; Striem-Amit et al., 2011a), there is a crucial need to better understand the reorganization following progressive RP visual loss to overcome this potential issue in the context of sight restoration.

The present study thus used brain resting-state to characterize the functional connectivity between Broca's area and sub-regions of the visual cortex in: (1) individuals suffering from RP who still retain central "tunnel vision" - the RP tunnel vision group; and (2) individuals with more severe RP so that now there is not even tunnel vision, and visual loss covers the entire visual field, leading to blindness (please note that such patients might still occasionally 
have faint light perception but zero form vision, as in advanced disease most individuals report some visual fluctuation, described as "good days and bad days" (see Heckenlively, 1988) - the RP blind group (3) sighted individuals - the sighted control group. The following specific questions were explored:

(1) What is the pattern of functional connectivity between Broca's area and visual areas in the sighted? Does this pattern show negative FC as might be predicted based on the deactivation (negative BOLD) in V1 to language and memory tasks (Azulay et al., 2009)?

(2) Do Broca's and visual areas exhibit a different pattern of functional connectivity in the RP blind (e.g. reversal to positive FC)?

(3) What is the functional connectivity of these same regions for RP tunnel vision subjects? Is a complete lack of visual input necessary for the development of such changes?

(4) Does this pattern vary according to the topography of the visual retinotopic areas; e.g. does the peripheral visual cortex show a different pattern of connectivity than the foveal across groups, as might be predicted by the fact that at the tunnel vision stage, the disease affects more peripheral than central areas of the visual field? 


\section{Materials and methods}

2.1. Subjects and ethics: The sample was made up of 35 subjects divided into 3 groups. Subjects were matched for age, and no subject had any reported neurological or psychiatric antecedents (Table 1).

- 11 retinitis pigmentosa (RP) tunnel vision subjects (four women; eight righthanded), presenting a residual central visual field limited to a 10-20 degree diameter (as evaluated by Goldmann III/4 kinetic perimetry), with a bestcorrected visual acuity equal or superior to 20/40 (measured by EDTRS charts). Ages ranged from 28 to 63 years (mean: 47.9, median: 55.0). None read Braille.

- 11 RP blind subjects (six women; all right-handed), as defined by a complete loss of the entire visual field that might be accompanied by some form of bare light perception. Ages ranged from 29 to 62 years (mean: 50.1, median: 56). Six were Braille readers.

- 13 Sighted controls (eight women; 12 right-handed), with unremarkable routine ophthalmological examinations (normal visual acuity and visual field, as evaluated by Goldmann III/4 kinetic perimetry). Ages ranged from 28 to 63 years (mean: 49.2, median: 54.0). None read Braille.

The Ethics Committee (Comité de protection des personnes, Ile de France V, and Agence Nationale de Sécurité du Médicament et des Produits de Santé) approved the experimental 
protocol (number 12873), and all subjects gave their written informed consent (according to the Declaration of Helsinki) before participating.

2.2. Functional imaging: fMRI was conducted on a whole-body $3 \mathrm{~T}$ clinical imager (Sigma Horizon) by using an 8-channel head coil. In each scanning sequence, 32 contiguous axial T2*-weighted gradient-echo echo-planar images (TE/TR, 93/3000 ms; FOV, $240 \times 240$ mm; matrix, $64 \times 64$; voxel size, $3.75 \times 3.75 \times 4 \mathrm{~mm}$; thickness, $4 \mathrm{~mm}$; interslice spacing, $0 \mathrm{~mm}$; NEX, 1) were recorded to encompass the entire brain. 180 volumes were acquired including 4 "dummy" volumes obtained at the start of the session. The scan duration was 9.25 minutes for the echo planar imaging sequence. Off-line, T2*-weighted images were co-registered and overlaid on the corresponding anatomic T1-weighted gradient-echo images (TE/TR/flip angle, 3.9/9.5 ms/20; FOV, $25.6 \times 25.6 \mathrm{~mm}$; matrix, $512 \times 512$; source voxel size, $1.2 \times 0.5 \times 0.5$ mm converted to $1 \times 1 \times 1 \mathrm{~mm}$; thickness, $1.2 \mathrm{~mm}$; interslice spacing, $1.2 \mathrm{~mm}$ ). During the scan, subjects were supine in the magnetic resonance imaging scanner and wore earplugs to compensate for the noisy environment. Subjects were instructed to keep their eyes closed. No explicit task was required.

2.3. FMRI preprocessing: fMRI data were preprocessed using the BrainVoyager QX 2.8 software package (Brain Innovation, Maastricht, Netherlands) and complementary software written in MATLAB R2009a (MathWorks, USA). Preprocessing of functional scans included: slice-time correction, 3D motion correction (no head motion exceeded $2 \mathrm{~mm}$ in any direction; which means movements are maximum in the order of magnitude of one functional voxel only as voxels size was: $3.75 \times 3.75 \times 4 \mathrm{~mm}$ ) in order to control and remove artifacts, bandpass filtering between 0.01 and $0.1 \mathrm{~Hz}$ to regress non-relevant frequencies (e.g. breathing, 
pulse), voxel-to-voxel linear regression (Cole et al., 2010) of spurious signal from the white matter and ventricles regions anatomically defined for each subject, normalization in the Talairach coordinate system in the volume (Talairach and Tournoux, 1988), and spatial smoothing with a Gaussian filter kernel of $6 \mathrm{~mm}$ full-width-at-half-maximum. We did not include global signal removing because of the potential introduction of false negative correlations (see Murphy et al., 2009). For the between groups comparison we tested and found no significant difference (or even a trend) in the extent $(\mathrm{mm})$ of head movement between the three groups (ANOVAs: p>0.05 for each direction: $\mathrm{X}, \mathrm{Y}, \mathrm{Z}$, translations, $\mathrm{X}, \mathrm{Y}, \mathrm{Z}$, rotations; see Supplementary Table. S1). These data were confirmed by repeating the GLM analysis (see section 2.4) including the head movement predictors (control analysis; see Supplementary Fig. S1). Including these movement predictors in the GLM did not change the main results.

2.4. Seed ROI definition and analysis: For each subject, a seed region-of-interest (ROI) consisting of a 5mm-radius sphere was located in Broca's area (BA45, pars triangularis; Talairach coordinates: -39, 17, 11; see (Burton et al., 2002a; Sarubbo et al., 2013)) which served to extract the blood-oxygen level-dependent time-course of this region (Burton et al., 2003). The average time-course for each subject was calculated, z-transformed and used as individual predictors in a group random-effect analysis based on the general linear model (GLM) (see Fig. 1; Friston et al., 1999). To establish a contrast among groups, a betweensubject random effect ANOVA was performed with a significance level of $p<0.05$, corrected for multiple comparisons using cluster-size thresholding (Forman et al., 1995; Goebel et al., 2006; Striem-Amit et al., 2015) implemented in BrainVoyager using the Monte Carlo simulation approach (see Figs. 2 and 3). This method takes the data contiguity of neighboring 
voxels directly into account and corrects for the false-positive rate of continuous clusters (a set-level statistical inference correction; corrected to $\mathrm{p}<0.05)$.

2.5. External functional localizers: External functional localizers were used to define the seed ROI from visual localizers (left hemisphere foveal V1, peripheral V1). Each of these localizers was extracted from a group of sighted controls and analyzed in normalized Talairach space using a random effect GLM, which enabled generalization of the findings to the population (see details below; Friston et al., 1999).

To define the primary visual cortex seeds, 13 control subjects were scanned in a standard phase-encoded retinotopic mapping procedure, with ring (eccentricity mapping) and wedge (polar mapping) stimuli to establish the visual retinotopic mapping (Engel et al., 1994; Sereno et al., 1995; Striem-Amit et al., 2015; Wandell et al., 2007; Wandell and Winawer, 2011) delivered during the two separate experiments. The stimuli were projected via an LCD screen positioned over the subject's forehead and watched through a tilted mirror. In Experiment 1 an annulus was projected, expanding from $0^{\circ}$ to $34^{\circ}$ of the subject's visual field in 30 seconds, repeated 10 times. Experiment 2 included a wedge with a polar angle of $22.5^{\circ}$ that rotated around the fixation point, and completed a cycle in 30 seconds repeated 20 times. Both the annulus in Experiment 1 and the wedge in Experiment 2 contained a flickering $(6 \mathrm{~Hz})$ radial checkerboard pattern with respect to standard retinotopic procedures (Engel et al., 1994) for the mapping of field maps. In both cases, there was a 30 second mute period before and after the visual stream for baseline. Group phase analysis was conducted on the two experiments as done in other studies from our group (Hertz and Amedi, 2010; Striem-Amit et al., 2011b) resulting in group maps of eccentricity and angle mapping. Angle mapping was then used to 
define the borders of V1, and the two maps were used to segregate it according to eccentricity (center or periphery of the visual field), laterality (left or right parts of the visual field).

The external functional definition of the early visual cortex was further used to calculate the within-subject correlation between Broca's area and left posterior or anterior calcarine sulcus and cuneus (localizers for the left fovea and the periphery of V1 respectively). Individual average time-courses from ROIs were sampled from each participant. The Pearson correlation coefficient between the time-courses of the two ROIs (within each subject) was calculated (see Fig. 4). ANOVA and Sheffe post-hoc analyses were also performed to test for differences between the groups $(\mathrm{p}<0.05)$. Then, non-parametric Wilcoxon rank sum tests were run on the same data to control for the effect of Braille reading skills in segregated populations of RP blind subjects (see Supplementary Table S2).

To evaluate the effect of age, blindness duration and Braille reading skills (see Supplementary Table S2) on the FC between Broca's area and the extrastriate areas of RP blind subjects, 5mm-radius spheres were defined according to the most significant foci exhibiting positive FC at the within-group level (i.e. left inferior occipital gyrus, -24 -89-18; left middle occipital gyrus -26 -89 4; left fusiform gyrus -24 -62 -7; left parahippocampal gyrus -24 -39-8; see Fig. 3). Then, non-parametric Wilcoxon rank sum and Pearson tests were performed on the correlation coefficients of Broca's area and each of these extrastriate regions in segregated populations of the RP blind subjects (Braille reader vs. non-Braille readers; see Supplementary Table S2).

To summarize, the resting-state data were analyzed by several complementary methods and levels. First, ROI-based seed functional connectivity analysis was performed on the rs-fMRI data to investigate the functional connectivity between the seeded Broca's area and the rest of the brain within each group (see Fig. 1). Next, ANOVAs and post-hoc tests were carried out 
to compare functional maps between groups (see Figs. 2-4; Table 2). FC coefficients between specific ROIs such as Broca's area and the anterior and posterior regions of the calcarine sulcus were also calculated for each group (see Fig. 4). ANOVAs and post-hoc tests were then performed on the mean z-score correlation coefficients to compare the groups. Finally, non-parametric Wilcoxon rank sum tests and Pearson tests were performed on the level of correlation of Broca's area and both the striate and extrastriate visual areas to control for the effects of age, duration of blindness and Braille reading skills in RP blind subjects (see Supplementary Table S2).

\begin{tabular}{|c|c|c|c|c|c|c|c|c|c|c|c|}
\hline Subject & Sex & Age & Cause of blindness & Light perception & $\begin{array}{c}\text { Left eye } \\
\text { Visual acuity (logmar) }\end{array}$ & $\begin{array}{c}\text { Right eye } \\
\text { Visual acuity (logmar) }\end{array}$ & $\begin{array}{c}\text { Left eye } \\
\text { Visual field diameter (") }\end{array}$ & $\begin{array}{c}\text { Right eye } \\
\text { Visual field diameter (") }\end{array}$ & $\begin{array}{c}\text { Blindness duration } \\
\text { (years) }\end{array}$ & Handedness & Braille \\
\hline B1 & $F$ & 29 & Retinitis pigmentosa & NLP & None & None & 0 & 0 & 8 & $R$ & Yes \\
\hline B2 & $\mathrm{F}$ & 57 & Retinitis pigmentosa & BLP & None & None & 0 & 0 & 17 & $\mathrm{R}$ & Yes \\
\hline B3 & $\mathrm{F}$ & 31 & Retinitis pigmentosa & BLP & None & None & 0 & 0 & 10 & $\mathrm{R}$ & Yes \\
\hline B4 & H & 62 & Retinitis pigmentosa & BLP & None & None & 0 & 0 & 19 & $\mathbf{R}$ & Yes \\
\hline B5 & H & 44 & Retinitis pigmentosa & BLP & None & None & 0 & 0 & 14 & R & No \\
\hline B6 & H & 56 & Retinitis pigmentosa & BLP & None & None & 0 & 0 & 7 & R & Yes \\
\hline B7 & $\mathrm{H}$ & 44 & Retinitis pigmentosa & BLP & None & None & 0 & 0 & 4 & R & No \\
\hline B8 & $\mathrm{F}$ & 60 & Retinitis pigmentosa & BLP & None & None & 0 & 0 & 15 & $\mathbf{R}$ & Yes \\
\hline B9 & $\mathrm{F}$ & 47 & Retinitis pigmentosa & BLP & None & None & 0 & 0 & 12 & $\mathbf{R}$ & No \\
\hline B10 & H & 59 & Retinitis pigmentosa & BLP & None & None & 0 & 0 & 6 & $\mathrm{R}$ & No \\
\hline B11 & $\mathrm{F}$ & 62 & Retinitis pigmentosa & BLP & None & None & 0 & 0 & 6 & $\mathrm{R}$ & No \\
\hline TV1 & H & 28 & Retinitis pigmentosa & - & 0 & 0.15 & 15 & 15 & $\cdot$ & $L / R$ & No \\
\hline TV2 & H & 55 & Retinitis pigmentosa & - & 0 & 0.1 & 10 & 15 & - & $\mathrm{R}$ & No \\
\hline TV3 & $\mathrm{F}$ & 62 & Retinitis pigmentosa & - & 0.3 & 0.2 & 10 & 10 & - & $\mathrm{R}$ & No \\
\hline TV4 & H & 62 & Retinitis pigmentosa & - & 0.1 & 0.1 & 10 & 10 & - & $\mathrm{R}$ & No \\
\hline TV5 & $\mathrm{F}$ & 43 & Retinitis pigmentosa & - & 0,1 & 0.1 & 15 & 15 & - & L & No \\
\hline TV6 & H & 60 & Retinitis pigmentosa & - & 0.3 & 0.2 & 10 & 10 & - & $L / R$ & No \\
\hline TV7 & $\mathrm{F}$ & 37 & Retinitis pigmentosa & - & 0.3 & 0.3 & 12 & 12 & - & $\mathrm{R}$ & No \\
\hline TV8 & H & 29 & Retinitis pigmentosa & - & 0.4 & 0.2 & 10 & 10 & - & R & No \\
\hline TV9 & $\mathrm{F}$ & 29 & Retinitis pigmentosa & - & 0 & 0 & 15 & 15 & - & $\mathrm{R}$ & No \\
\hline TV10 & H & 59 & Retinitis pigmentosa & - & 0.3 & 0.3 & 7 & 10 & - & $\mathrm{R}$ & No \\
\hline TV11 & H & 63 & Retinitis pigmentosa & - & 0.5 & 0.6 & 20 & 20 & - & $\mathrm{R}$ & No \\
\hline S1 & $\mathrm{F}$ & 42 & 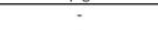 & - & 0 & 0 & $\mathrm{~N}$ & $\mathrm{~N}$ & - & $\mathrm{R}$ & No \\
\hline s2 & H & 58 & . & - & 0 & 0 & $\mathrm{~N}$ & $\mathrm{~N}$ & . & $R / L$ & No \\
\hline s3 & H & 31 & - & - & 0 & 0 & $\mathrm{~N}$ & $\mathrm{~N}$ & - & R & No \\
\hline S4 & $\mathrm{F}$ & 54 & - & - & 0 & 0 & $\mathrm{~N}$ & $\mathrm{~N}$ & - & $\mathbf{R}$ & No \\
\hline s5 & $\mathrm{F}$ & 28 & - & - & 0 & 0 & $\mathrm{~N}$ & $\mathrm{~N}$ & - & $R$ & No \\
\hline S6 & $\mathrm{F}$ & 36 & - & - & 0 & 0 & $\mathrm{~N}$ & $\mathrm{~N}$ & - & $R$ & No \\
\hline S7 & $\mathrm{F}$ & 59 & . & . & 0 & 0 & $\mathrm{~N}$ & $\mathrm{~N}$ & . & $\mathbf{R}$ & No \\
\hline S8 & $\mathrm{F}$ & 61 & - & - & 0 & 0 & $\mathrm{~N}$ & $\mathrm{~N}$ & - & $R$ & No \\
\hline S9 & H & 57 & - & - & 0 & 0 & $\mathrm{~N}$ & $\mathrm{~N}$ & - & $R$ & No \\
\hline $\mathrm{S} 10$ & H & 59 & . & - & 0 & 0 & $\mathrm{~N}$ & $\mathrm{~N}$ & - & $R$ & No \\
\hline S11 & $\mathrm{F}$ & 63 & - & - & 0 & 0 & $\mathrm{~N}$ & $\mathrm{~N}$ & - & $\mathrm{R}$ & No \\
\hline $\mathrm{S} 12$ & $\mathrm{~F}$ & 54 & - & - & 0 & 0 & $\mathrm{~N}$ & $\mathrm{~N}$ & - & $R$ & No \\
\hline $\mathrm{S} 13$ & $\mathrm{H}$ & 56 & - & - & 0 & 0 & $\mathrm{~N}$ & $\mathrm{~N}$ & - & $R$ & No \\
\hline
\end{tabular}

Table 1. Subjects' clinical data. B: RP blind subjects, TV: RP tunnel vision subjects. S: sighted control subjects. N: Normal visual field, i.e. $130^{\circ}-140^{\circ}$ in horizontal diameter. Blindness duration: number of years since the subjects lost any form vision in all parts of their visual field but might still keep some bare light perception. BLP: Bare light perception. NLP: No light perception. 


\section{Results}

\section{Please insert figure 1 here}

Fig. 1. Within-group analysis of functional connectivity seeded from Broca's area. The maps are shown in fmri full-slice view (neurological convention) for (A) Sighted controls, (B) RP tunnel vision, (C) RP blind subjects. Colors depict the magnitude of the FC of Broca's area localizer and the rest of the brain: yelloworange for positive FC and green-blue for negative FC. X, y, z are in Talairach coordinates. In all groups, the inferior frontal Broca's area is functionally connected to the anterior cingulate, left supramarginal gyrus (e.g. Wernicke's area), subcortical regions (e.g. bilateral insula, thalamus), superior temporal auditory regions and bilateral fronto-parietal regions. (A) The sighted control subjects show a strong negative FC of Broca's area with major ventral and dorsal visual areas (i.e. along the calcarine sulcus/lingual, cuneus, inferior occipital, middle occipital, parahippocampal, restrosplenial, fusiform, and inferior temporal gyri) and medial part of the superior frontal gyrus. (B) RP tunnel vision subjects show almost no negative FC of Broca's area with calcarine sulcus/cuneus but still preserve a negative FC with the inferior occipital, middle occipital, lingual, parahippocampal, restrosplenial, fusiform, and inferior temporal gyri. (C) RP blind subjects show positive FC of Broca's area with the calcarine sulcus/cuneus and lose almost all negative functional connectivity with the other extrastriate visual areas.

In all groups, the data showed that Broca's area was functionally connected to the anterior cingulate, left supramarginal gyrus (Wernicke's area), the precentral gyrus (e.g. primary motor area), and the subcortical (e.g. bilateral insula, thalamus), auditory (e.g. A1) and frontoparietal regions (see Fig. 1).

In the sighted control within-group analysis, there was strong negative FC between Broca's area and early and high order visual areas as well as the medial part of the superior frontal gyrus. These included the major ventral and dorsal visual areas along the calcarine 
sulcus (corresponding to Brodmann Area 17 / Visual area V1 - Primary visual cortex), cuneus, inferior occipital, lingual, parahippocampal, retrosplenial, fusiform, and inferior temporal gyri (see Fig. 1A).

The RP tunnel vision within-group analysis revealed almost no negative FC between Broca's area and the calcarine sulcus and cuneus but still preserved negative FC with the inferior occipital, lingual, parahippocampal, restrosplenial, fusiform, and inferior temporal gyri (see Fig. 1B).

The RP blind group showed a complete reversal of the level of FC between Broca's area and the early visual cortex. The data showed positive FC between Broca's area and the calcarine sulcus/cuneus, but almost all the negative FC with other visual areas was lost (see Fig. 1C).

\section{Please insert figure 2 here}

Fig. 2. Between-groups analysis of functional connectivity seeded from Broca's area (focus on calcarine sulcus/cuneus differences). The maps are shown in fmri full-slice view (neurological convention) for (A) RP blind subjects or (B) RP tunnel vision subjects compared to the sighted control subjects. Colors depict the magnitude of the difference between groups of the FC of Broca's area localizer and the rest of the brain: yelloworange for increased FC (away from zero) and green-blue for decreased FC (toward zero). X, Y, Z are Talairach coordinates. (A) Increased functional connectivity was found in RP blind subjects compared to sighted control subjects between Broca's area and the calcarine sulcus (Brodmann area 17) delineated in white as well as the cuneus, lingual, fusiform, inferior occipital, parahippocampal and medial part of the superior frontal gyri. (B) Increased functional connectivity was found in RP tunnel vision subjects compared to the sighted control subjects between Broca's area and the anterior calcarine sulcus/Cuneus (Brodmann areas 17-18) and the medial part of the superior frontal gyrus. As between-groups differences could result from positive or (and) negative functional connectivity at the group level, we show the within-group maps for selected regions with a blow-up at 
the bottom of each figure. Yellow-orange and green-blue represent positive and negative functional connectivity respectively with Broca's area for each group. S: sighted controls. TV: RP tunnel vision. FB: RP blind.

\section{Please insert figure 3 here}

Fig. 3. Between-groups analysis of functional connectivity seeded from Broca's area (focus on extrastriate area differences). The maps are shown in fmri full-slice view (neurological convention) for RP blind subjects compared to $(\boldsymbol{A})$ sighted control subjects or $(\boldsymbol{B})$ RP tunnel vision subjects. Colors depict the magnitude of the difference between groups of the FC of Broca's area localizer and the rest of the brain: yellow-orange for increased FC (away from zero) and green-blue for decreased FC (toward zero). X, Y, Z are Talairach coordinates. (A) Increased functional connectivity was found in RP blind compared to the sighted control subjects between Broca's area and the left fusiform (FFG), parahippocampal (ParaH), inferior (IOG) and middle (MOG) occipital gyri (delineated in black). (B) Increased functional connectivity was found in RP blind subjects compared to RP tunnel vision subjects between Broca's area and the parahippocampal, inferior and middle occipital gyri (delineated in black). As between-groups differences could result from positive or (and) negative functional connectivity at the group level, we show the within-group maps for selected regions with a blow-up at the bottom of each figure. Yellow-orange and green-blue represent positive and negative functional connectivity respectively with Broca's area for each group. S: sighted controls. TV: RP tunnel vision. FB: RP blind. 


\begin{tabular}{|c|c|c|c|c|c|c|}
\hline Contrast peaks & Peak X & Peak Y & Peak Z & $\mathrm{t}$ value & p value & BA \\
\hline \multicolumn{7}{|l|}{ RP blind > Sighted control } \\
\hline LH Anterior calcarine sulcus/cuneus & -2 & -71 & 9 & 5.58 & 0.000 & 17 \\
\hline LH Posterior calcarine sulcus/lingual gyrus & -4 & -83 & -12 & 4.13 & 0.000 & 18 \\
\hline LH Inferior occiptal gyrus & -28 & -89 & -18 & 4.05 & 0.000 & 18 \\
\hline LH Middle/inferior occipital gyrus & -31 & -86 & -3 & 3.80 & 0.001 & 18 \\
\hline LH Fusiform gyrus & -25 & -62 & -9 & 4.57 & 0.000 & 37 \\
\hline LH Parahippocampal gyrus & -31 & -38 & -9 & 5.18 & 0.000 & 37 \\
\hline LH Inferior temporal gyrus & -52 & -14 & -18 & 4.61 & 0.000 & 38 \\
\hline LH Anterior cingulate/medial part of the superior frontal gyrus & -13 & 37 & 18 & 5.49 & 0.000 & $24 / 10$ \\
\hline RH Anterior calcarine sulcus/cuneus & 2 & -71 & 9 & 6.30 & 0.000 & 17 \\
\hline RH Posterior calcarine sulcus/cuneus & 8 & -89 & 0 & 2.84 & 0.008 & 17 \\
\hline RH Inferior temporal gyrus & 23 & 1 & -33 & 3.15 & 0.004 & 38 \\
\hline Medial part of the superior frontal gyrus & 2 & 46 & 33 & 5.06 & 0.000 & 9 \\
\hline \multicolumn{7}{|l|}{ Sighted control > RP blind } \\
\hline LH Postcentral gyrus & -25 & -32 & 63 & -4.46 & 0.000 & 5 \\
\hline LH Precentral gyrus & -7 & -17 & 60 & -3.87 & 0.001 & 4 \\
\hline RH Superior parietal lobe & 17 & -50 & 45 & -5.66 & 0.000 & 7 \\
\hline RH Supramarginal gyrus & 53 & -32 & 39 & -4.85 & 0.000 & 40 \\
\hline RH Cingulate gyrus & 14 & -35 & 30 & -3.07 & 0.004 & 31 \\
\hline RH Precentral gyrus & 14 & -17 & 63 & -4.41 & 0.000 & 4 \\
\hline RH Middle frontal gyrus & 35 & 34 & 30 & -3.98 & 0.000 & 9 \\
\hline RH Inferior frontal gyrus & 53 & 1 & 18 & -3.10 & 0.004 & 6 \\
\hline RH Superior temporal gyrus & 38 & -38 & 15 & -4.03 & 0.000 & 39 \\
\hline RH Insula & 29 & 1 & 15 & -4.00 & 0.000 & - \\
\hline RH Thalamus & 20 & -17 & 18 & -3.40 & 0.002 & - \\
\hline \multicolumn{7}{|l|}{ RP tunnel vision $>$ Sighted control } \\
\hline LH Anterior calcarine sulcus/cuneus & -4 & -71 & 9 & 4.70 & 0.000 & 17 \\
\hline LH Anterior cingulate & -13 & 22 & 21 & 2.57 & 0.015 & 24 \\
\hline LH Superior frontal gyrus & -13 & 31 & 30 & 3.71 & 0.001 & 9 \\
\hline RH Anterior calcarine sulcus/cuneus & 2 & -68 & 9 & 4.12 & 0.000 & 17 \\
\hline RH Lingual gyrus & 8 & -65 & 9 & 3.91 & 0.000 & 17 \\
\hline Medial part of the superior frontal gyrus & 11 & 49 & 21 & 3.06 & 0.004 & 10 \\
\hline \multicolumn{7}{|l|}{ Sighted control > RP tunnel vision } \\
\hline RH Superior parietal lobe & 30 & -47 & 51 & -2.50 & 0.018 & 7 \\
\hline RH Supramarginal gyrus & 47 & -35 & 30 & -3.32 & 0.002 & 40 \\
\hline \multicolumn{7}{|l|}{ RP blind > RP tunnel vision } \\
\hline LH Middle occipital gyrus & -28 & -86 & 0 & 4.04 & 0.000 & 17 \\
\hline LH Inferior occipital gyrus & -28 & -89 & -18 & 5.18 & 0.000 & 18 \\
\hline LH Parahippocampal gyrus & -28 & -41 & -6 & 3.22 & 0.003 & 37 \\
\hline \multicolumn{7}{|l|}{ RP tunnel Vision > RP blind } \\
\hline LH Precuneus & -19 & -26 & 33 & -3.38 & 0.002 & 24 \\
\hline RH Superior parietal cortex & 17 & -47 & 45 & -4.38 & 0.000 & 7 \\
\hline RH Primary motor cortex & 23 & -20 & 45 & -3.04 & 0.005 & 4 \\
\hline
\end{tabular}

Table 2. Peaks of functional connectivity differences between groups (seed region-of-interest: Broca's area). Peaks $x, y, z:$ Talairach coordinates. P values corrected for multiple comparisons. LH: Left hemisphere. RH: Right hemisphere. BA: Brodmann areas. 
In the RP blind subjects compared to the sighted controls, between-group analyses revealed a significantly increased level of FC between Broca's area and parts of the calcarine sulcus, cuneus, lingual, left fusiform, left inferior occipital, left parahippocampal, left inferior temporal and medial part of the superior frontal gyri (see Figs. 2A and 3A; for Talairach coordinates of all the peaks for these contrasts see Table 2).

Increased FC between Broca's area and the anterior calcarine sulcus/cuneus as well as the medial part of the superior frontal gyrus was found for the RP tunnel vision subjects compared to the sighted controls (see Fig. 2B; for Talairach coordinates of all the peaks for these contrasts see Table 2).

Compared to the RP tunnel vision subjects, the RP blind subjects showed increased FC between Broca's area and specific extrastriate areas such as the left middle occipital, inferior occipital and parahippocampal gyri (see Fig. 3B, Table 2).

\section{Please insert the figure 4 here}

Fig. 4. Correlations between Broca's area and specific parts of the calcarine sulcus across populations (RP blind, RP tunnel vision, sighted control subjects). Correlations ( $R^{2}$ Pearson test; mean z-score) of Broca's area with $(\boldsymbol{A})$ left anterior or $(\boldsymbol{B})$ left posterior calcarine sulcus was calculated for each group. Bars indicate between-subject standard error. (A) There was a group main effect for the correlation between the left anterior calcarine sulcus and Broca's area (ANOVA: $F(2,32)=13.59 p<0.0001)$. Post-hoc tests (Scheffe) revealed significant differences between the RP blind and sighted control subjects' correlation coefficients $(* * p<0.01)$, and between RP tunnel vision and sighted control subjects (* $p<0.05)$. (B) There was a main effect for the correlation between the groups for the left posterior calcarine sulcus and Broca's area $($ ANOVA: $F(2,32)=5.78$ p $<0.01$ ). Post-hoc tests (Scheffe) only revealed significant differences between the RP blind and the sighted control correlation coefficients $(* * p<0.01)$. For each group, mean $R^{2}$ coefficients before $Z$ transformation are mentioned. 
In terms of correlation coefficients between ROIs, there was a group main effect for both the left anterior (ANOVA: $\mathrm{F}(2,32)=13.6 \mathrm{p}<0.0001$ ) and posterior (ANOVA: $\mathrm{F}(2,32)=5.78$ p $<0.01$ ) calcarine sulcus and Broca's area (see Fig. 4). Post-hoc tests showed (1) a statistically significant difference for both the anterior and posterior regions of the calcarine sulcus and Broca's area between the RP blind and the sighted control subjects $(p<0.01$; see Fig. 4A-B), and (2) a statistically significant difference solely for the anterior regions of the calcarine sulcus and Broca's area in the RP tunnel vision subjects and the sighted controls $(\mathrm{p}<0.05$; see Fig. 4A).

In the RP blind subjects, Pearson tests revealed no effect for age or blindness duration on the FC between Broca's area and the anterior calcarine sulcus/cuneus (age: $R(9)=0.32 \mathrm{p}>0.05$; blindness duration: $\mathrm{R}(9)=0.24 \mathrm{p}>0.05$ ), posterior calcarine sulcus/cuneus (age: $\mathrm{R}(9)=0.49$ $\mathrm{p}>0.05$; blindness duration: $\mathrm{R}(9)=-0.14 \quad \mathrm{p}>0.05)$, left inferior occipital gyrus (age: $R(9)=-0.024 p>0.05$; blindness duration: $R(9)=0.18 p>0.05$ ), left fusiform gyrus (age: $R(9)=0.51 \mathrm{p}>0.05$; blindness duration: $\mathrm{R}(9)=0.094 \mathrm{p}>0.05$ ), and left parahippocampal gyrus (age: $\mathrm{R}(9)=0.23 \mathrm{p}>0.05$; blindness duration: $\mathrm{R}(9)=-0.12 \mathrm{p}>0.05)$. 


\section{Discussion}

In this rs-fMRI study, we explored the FC between Broca's area (BA45, pars triangularis of the inferior frontal gyrus) and visual areas in sighted subjects as well as in two groups of subjects suffering from late onset retinitis pigmentosa (RP), one with tunnel vision (partial blind) and the other RP blind (covering the entire visual field). These groups exhibited negative, null and positive FC patterns respectively (see Fig. 1). Furthermore, in comparison to the sighted controls, both groups of RP subjects presented increased FC between Broca's area and regions of the calcarine sulcus and cuneus that are specifically deprived according to the evolution of their condition (i.e. the anterior part (peripheral V1) for the RP tunnel vision subjects, and both anterior and posterior part of V1 for the RP blind subjects; see Figs. 2 and 4, Table 2). Finally, compared to both the sighted control and the RP tunnel vision subjects, the RP blind showed increased FC between Broca's area and specific extrastriate areas including the left parahippocampal, fusiform, inferior and middle occipital gyri (see Fig. 3, Table 2).

4.1. Negative functional connectivity between Broca's area and visual areas in the sighted control group

Several studies support the claim that negative correlations reflect a true reduction in neuronal processing (Behzadi et al., 2007; Chai et al., 2014; Fox et al., 2005; Guerra-Carrillo et al., 2014; Logothetis et al., 2009; Shmuel et al., 2006, 2002; Shulman et al., 1997; Zeharia et al., 2012). 
In the current study, Broca's area in the sighted control group exhibited strong negative FC with the entire calcarine sulcus/cuneus (i.e. V1) and both the ventral and dorsal extrastriate visual areas. This is in agreement with a fMRI study which reported that in a verbal memory retrieval task, sighted subjects showed activation of classical language areas (including Broca's area) coupled with strong deactivation of visual areas including V1 calcarine sulcus and cuneus (Azulay et al., 2009). These study argued that a balance between activation and deactivation is required to filter out irrelevant information and enable an attentional focus on internal representations. This may imply that the negative FC we observed between language/control at rest (i.e. the intrinsic system) and visual (i.e. the extrinsic system) networks could reflect a functional competition that prevents visual inputs from disturbing language processing (for reviews of extrinsic and intrinsic systems see (Fox et al., 2005; Golland et al., 2008, 2007)). Broca's area in the sighted control group also showed negative FC with the medial part of the superior frontal gyrus. We assume based on its anatomical location (talairach coordinates: $-1,47,-4$; see Fox etl al., 2005), that it is part of the defaultmode network. In healthy subjects, default-mode network regions are well known to be deactivated in a set of functional tasks (e.g. language), and activated in rest conditions, and would contribute to the emergence of spontaneous inner-oriented thoughts (Greicius et al., 2003; Raichle et al., 2001).

\subsection{Differences in Broca's area functional connectivity to the calcarine sulcus/cuneus in the three groups}

The results help clarify whether the pattern of connectivity can help to support language recruitment in visual areas in subjects with late visual deficits or partial visual deficits like tunnel vision. Burton et al. argued that recruitment can occur in both early and late blind 
subjects, and that it may be related to the learning of Braille reading (Burton et al., 2002a). More recently, Bedny et al. (2012) only found language-related activation of V1 in early but not in late blind participants (Bedny et al., 2012). They argued that the V1 activation observed in the late blind in previous studies reflects attention or preparation mechanisms and concluded that the recruitment of the visual cortex for language processing depends on the age of blindness onset (Bedny et al., 2012).

In the current study, the RP blind group exhibited positive Broca's area FC with parts of the calcarine sulcus/cuneus and increased FC of the same regions compared to the sighted controls (see Figs. 1C-2A), which completely reversed the picture of resting state functional connectivity found in the sighted. In the RP blind subjects, the entire visual field is lost, which is probably why the FC to Broca's area stretched from the anterior to the posterior deprived regions of the calcarine sulcus/cuneus (corresponding to early visual areas). However, no evidence for a FC difference was found between Broca's area and regions implicated in attentional mechanisms between groups. In contrast to the hypothesis put forward by Bedny et al. (2012), we suggest that our results might support the recruitment of the early visual areas by the language system, even in blind subjects with previous visual experience, or at least, that the basis for such recruitment emerges from the resting-state functional connectivity pattern. On the other hand, our data do not support the notion that this recruitment is tightly linked to the acquisition of Braille reading skills (Burton et al., 2002a, 2002b; Cunningham et al., 2015) since we did not find significant differences between Braille and non-Braille readers within the RP blind group (see Supplementary Table S2). Thus, the functional relevance of this connectivity still remains unclear. We also evaluated the effect of age and blindness duration, and found no correlation with the FC between Broca and V1. Overall, these data suggest that there is no critical age for developing functional connectivity between Broca's 
area and early visual areas or for the complete reversal of their sign from negative FC in the sighted to positive in RP complete late blindness.

The data for the RP tunnel vision subjects were generally consistent with what was found for the RP blind in the sense that they support the hypothesis that recruitment for language processing is specific to visually deprived regions. They also demonstrate that these processes cannot only occur in the blind but also in subjects with residual visual function.

The RP tunnel vision subjects showed a slight negative FC of Broca's area with the calcarine sulcus/cuneus (Brodmann area 17; see Fig. 1). However, when compared to the sighted subjects, the RP tunnel vision subjects presented increased FC between Broca's area and specific visually deprived regions (i.e., the anterior but not the posterior part of the calcarine sulcus/cuneus; see Figs. 2 and 4).

In sighted individuals, the anterior and posterior parts of the calcarine sulcus/cuneus code for peripheral and foveal representations of the visual field respectively (Sereno et al., 1995). In the RP tunnel vision subjects, however, the peripheral representation of the visual field is lost whereas the foveal field is preserved (Kalloniatis and Fletcher, 2004). Based on the intermodality competition hypothesis (Azulay et al., 2009), and given the intra-group null FC for the tunnel vision group, in conjunction with their increased FC compared to the sighted, we suggest that the language network develops functional connectivity with the sensory deprived early visual cortex and that this connectivity is limited by the remaining foveal vision input. Furthermore, the selective changes observed in the anterior V1 may be related to function reallocation facilitated by the putative cross-modal abilities of this area (Eckert et al., 2008; Falchier et al., 2002; Wandell and Smirnakis, 2009). It would be worthwhile comparing RP tunnel vision subjects with other clinical conditions in which patients present with central 
vision loss (e.g. age-related macular degeneration, Stargardt disease) to test whether the posterior/foveal regions of V1 are also functionally connected to the language network.

Thus overall, these findings suggest that (1) dramatic changes occur in functional connectivity between the language and early visual areas of the adult brain that change the sign of the FC from negative to positive; (2) these changes occur even in a partial visual defect condition, though to a lesser extent; and (3) these changes presumably depend on the topography of the functionally deprived areas.

\subsection{Differences in Broca's area functional connectivity to extrastriate areas in the} three groups

RP blind subjects also exhibited increased FC between Broca's area and a set of extrastriate regions as compared to both RP tunnel vision and sighted subjects (see Fig. 3, Table 2) but not with the lateral occipital regions. Most of these regions have been identified in verb generation tasks on the late blind (Burton et al., 2003, 2002a). It was suggested that multisensory regions transfer language functions to tactile or auditory stimuli. Our results challenge this explanation for two main reasons: (1) we did not find any significant functional connectivity changes between Broca's area and these regions in Braille as compared to nonBraille readers (see Supplementary Table S2); (2) we did not find any significant difference in functional connectivity between the auditory and extrastriate visual areas across groups, as would be expected according to the auditory cross-modality hypothesis (Burton et al., 2002a).

These extrastriate visual areas have also been identified in verbal and semantic retrieval task studies in the congenitally blind (Amedi et al., 2003; Azulay et al., 2009; 
Noppeney et al., 2003; Raz et al., 2005). Hence increased FC between Broca's area and these extrastriate regions may reflect the lifting of inhibition of the visual association cortex to process verbal memory and semantic information. Nevertheless, the specific differences between the functional connectivity of these regions in RP blind compared to the RP tunnel vision subjects support the idea that complete vision loss is required for such changes to occur.

4.4. Preserved functional connectivity between Broca's area and the rest of the brain in the three groups

In all three groups, we identified regions that are regularly activated in functional language tasks and also belong to several intrinsically connected networks such as the language network (Bookheimer, 2002; Hagoort, 2005; Hampson et al., 2002; Johnson and Ojemann, 2000; Price, 2010; Yetkin et al., 1995) and the executive control network (Doucet et al., 2011; Spreng et al., 2010; Sundermann and Pfleiderer, 2012; Vincent et al., 2008). These findings suggest that functional connectivity is useful in delineating networks for a given function, including language, and may imply that beyond the changes between Broca's and visual areas, the rest of the network is well preserved in cases of visual deprivation.

4.5. No sensitive period for the development of cross-modal plasticity at least as reflected by the rs-fMRI data

The massive changes observed in functional connectivity between language and visual areas in the late blind support the notion that some level of reorganization even in the calcarine 
sulcus / V1 can occur in the adult brain. This change in connectivity was gradual and quite dramatic in term of the distance between these areas and the different functions they support. The fact that the tunnel vision subjects exhibited an intermediate pattern reinforces this idea and further suggests that it occurs not only after complete visual deprivation, but also in the context of partial visual loss. These observations strengthen arguments from the field of stroke rehabilitation where musical stimulation (Särkämö et al., 2008) as well as noninvasive stimulation devices (Di Pino et al., 2014) enhanced recovery in aphasia, probably by influencing the way information is processed in alternative networks. Taken together, these data imply that following input loss or damage to a certain network, the adult brain preserves the ability to functionally connect with other networks and to potentially optimize their performance. Nevertheless, the challenge of selecting the appropriate way to harness this functional connectivity for optimal behavioral recovery in such clinical conditions as stroke or visual restoration via retinal prostheses is still to be addressed. It is also not clear whether these changes are compensatory in nature or whether they simply underlie connections in the adult brain and furnish the 'raw material' for task-related compensatory plasticity.

\subsection{Limitations and methodological considerations}

Rs-fMRI is an invaluable sensitive tool to detect changes in brain connectivity (Fox and Greicius, 2010; Guerra-Carrillo et al., 2014; Smith et al., 2009). However, it should be mentioned that this method is subject to reliability problems induced by movement (a main confound) but also by mind wandering, or wakefulness state (Caceres et al., 2009; Tagliazucchi et al., 2012; van Dijk et al., 2012). This is why we took extra measures in order to control for head movement and verify that there was no significant difference in head movements between the groups. In our study, this method allowed us to delineate regions that 
are classically activated in functional language tasks and also belong to the intrinsic language network (Bookheimer, 2002; Hagoort, 2005; Hampson et al., 2002; Johnson and Ojemann, 2000; Price, 2010; Yetkin et al., 1995) supporting that our analysis is valid. Moreover, it allowed the identification of specific functional connectivity between Broca's area and V1. This result points towards probable plastic changes induced by visual loss. However, our approach does not allow a direct inference about the role of the increased FC between Broca's area and V1. Other approaches, such as language task-based fMRI (Burton et al., 2002a, 2003; Bedny et al., 2011, 2012) or transcranial magnetic resonance (Amedi et al., 2003) could provide complementary data to accurately establish the origin and the influence of this connectivity on processes that involve Broca's area. It should be noted that the limited availability of such relatively rare homogenous blind and tunnel vision subjects prevented us from extending the protocol to include these behavioral tasks or other interesting experiments such as retinotopy, at least not in this point of time. For instance, a retinotopy experiment in RP tunnel vision subjects would allow us to design seeds of different portions of V1 (i.e. underlying the projections of normal central and deprived peripheral visual field) and give an insight on the cross-modal FC changes occurring in their brain.

We should also specify that information on disease onset is lacking and therefore was not used as a covariate in our analysis. Indeed, in clinical practice, it is very hard to define the onset of RP because of fading and filling-in processes that could hide scotoma for years after the disease onset (see Pessoa and De Weerd, 2003).

As previously described in the discussion, several studies support that negative FC reflect a physiological neuronal processing (Behzadi et al., 2007; Chai et al., 2014; Fox et al., 2005; Guerra-Carrillo et al., 2014; Logothetis et al., 2009; Shmuel et al., 2006, 2002; Shulman et al., 1997; Zeharia et al., 2012) and may even have a role in cases of mental disorders (Whitfield- 
Gabrieli and Ford, 2012). Nevertheless, the interpretation of the negative correlation is subject to debate (Buckner et al., 2013). Indeed, several noise removal methods such as global signal regressions are believed to introduce false negative correlations (see Murphy et al., 2009). These preprocessing methods were not used in our study, which give us some confidence in the data interpretation. Additionally, note that we did not record breathing or pulse during the scan but that their frequencies were regressed out by the bandpass filtering preprocessing step.

\subsection{Conclusion}

The findings presented here showed increased functional connectivity between language and visual areas, which strengthened with the progression of RP from tunnel vision to complete blindness. The data suggest that the changes observed between the language and the visual areas depend on the topography of the functionally deprived regions. These results contribute to the debate on claims concerning a sensitive period for the development of cross-modal mechanisms between language and visual areas, at least in the context of large-scale functional connectivity patterns between areas.

Future studies could address (1) the functional recruitment of foveal V1 for language processing in central visual deficits (e.g. in age macular degeneration and Stargardt disease), (2) the behavioral counterparts of the functional connectivity changes observed in the present study, and their applicability to visual restoration (e.g. using retinal prosthesis) and substitution (e.g. using sensory substitution devices) processes (3) the functional connectivity changes of different regions (as seed) of $\mathrm{V} 1$ and the rest of the brain across populations. 


\section{Funding}

This work was supported by French State funding under the auspices of the Agence Nationale de la Recherche (ANR) within the Investissements d'Avenir program (ANR-11-IDEX-000402) and by a grant from Humanis. This work was conducted within the framework of the Labex LIFESENSES (ANR-10-LABX-65). This work was also supported by a European Research Council grant (grant number 310809 to AA), the James S. McDonnell Foundation scholar award (grant number 220020284 to AA), the Edmond and Lily Safra Center for Brain Sciences (ELSC) Vision center grant, the Maratier family and the Gatsby Foundation.

Conflict of interest: Norman Sabbah, None; Colas Nils Authié, None; Nicolae Sanda, None; Saddek Mohand-Said, None; José-Alain Sahel, consultant for Pixium Vision, GenSight Biologics, Sanofi-Fovea, Genesignal; Avinoam B. Safran, None; Christophe Habas, None; Amir Amedi, None.

\section{Acknowledgments}

We thank Sami Abboud, Shachar Maidenbaum, Ella Striem-Amit, Ilan Goldberg, Céline Devisme, Anne-Fleur Barfuss who provided valuable input and help on this work. 


\section{References}

Amedi, A., Floel, A., Knecht, S., Zohary, E., Cohen, L.G., 2004. Transcranial magnetic stimulation of the occipital pole interferes with verbal processing in blind subjects. Nat. Neurosci. 7, 1266-70. doi:10.1038/nn1328

Amedi, A., Raz, N., Pianka, P., Malach, R., Zohary, E., 2003. Early “visual” cortex activation correlates with superior verbal memory performance in the blind. Nat. Neurosci. 6, 758-66. doi:10.1038/nn1072

Ayton, L.N., Blamey, P.J., Guymer, R.H., Luu, C.D., Nayagam, D.A.X., Sinclair, N.C., Shivdasani, M.N., Yeoh, J., McCombe, M.F., Briggs, R.J., Opie, N.L., Villalobos, J., Dimitrov, P.N., Varsamidis, M., Petoe, M.A., McCarthy, C.D., Walker, J.G., Barnes, N., Burkitt, A.N., Williams, C.E., Shepherd, R.K., Allen, P.J., 2014. First-in-Human Trial of a Novel Suprachoroidal Retinal Prosthesis. PLoS One. doi:10.1371/journal.pone.0115239

Azulay, H., Striem, E., Amedi, A., 2009. Negative BOLD in sensory cortices during verbal memory: a component in generating internal representations? Brain Topogr. 21, 221-31. doi:10.1007/s10548-009-0089-2

Bavelier, D., Neville, H.J., 2002. Cross-modal plasticity: where and how? Nat. Rev. Neurosci. 3, 44352. doi:10.1038/nrn 848

Bedny, M., Pascual-Leone, A., Dodell-Feder, D., Fedorenko, E., Saxe, R., 2011. Language processing in the occipital cortex of congenitally blind adults. Proc. Natl. Acad. Sci. U. S. A. 108, 4429-34. doi:10.1073/pnas.1014818108

Bedny, M., Pascual-Leone, A., Dravida, S., Saxe, R., 2012. A sensitive period for language in the visual cortex: distinct patterns of plasticity in congenitally versus late blind adults. Brain Lang. 122, 162-70. doi:10.1016/j.bandl.2011.10.005

Behzadi, Y., Restom, K., Liau, J., Liu, T.T., 2007. A component based noise correction method (CompCor) for BOLD and perfusion based fMRI. Neuroimage 37, 90-101. doi:10.1016/j.neuroimage.2007.04.042

Bookheimer, S., 2002. Functional MRI of language: new approaches to understanding the cortical organization of semantic processing. Annu. Rev. Neurosci. 25, 151-88. doi:10.1146/annurev.neuro.25.112701.142946

Buckner, R.L., Krienen, F.M., Yeo, B.T.T., 2013. Opportunities and limitations of intrinsic functional connectivity MRI. Nat. Neurosci. 16, 832-7. doi:10.1038/nn.3423

Burton, H., Diamond, J.B., McDermott, K.B., 2003. Dissociating cortical regions activated by semantic and phonological tasks: a FMRI study in blind and sighted people. J. Neurophysiol. 90, 1965-82. doi:10.1152/jn.00279.2003

Burton, H., Snyder, A., Diamond, J.B., Raichle, M.E., 2002a. Adaptive changes in early and late blind: a FMRI study of verb generation to heard nouns. J. Neurophysiol. 88, 3359-71. doi:10.1152/jn.00129.2002

Burton, H., Snyder, A.Z., Conturo, T.E., Akbudak, E., Ollinger, J.M., Raichle, M.E., 2002b. Adaptive changes in early and late blind: a fMRI study of Braille reading. J. Neurophysiol. 87, 589-607.

Butt, O.H., Benson, N.C., Datta, R., Aguirre, G.K., 2013. The fine-scale functional correlation of striate cortex in sighted and blind people. J. Neurosci. 33, 16209-19. doi:10.1523/JNEUROSCI.0363-13.2013

Caceres, A., Hall, D.L., Zelaya, F.O., Williams, S.C.R., Mehta, M.A., 2009. Measuring fMRI reliability with the intra-class correlation coefficient. Neuroimage $45,758-768$. 
doi:10.1016/j.neuroimage.2008.12.035

Chai, X.J., Ofen, N., Gabrieli, J.D.E., Whitfield-Gabrieli, S., 2014. Selective Development of Anticorrelated Networks in the Intrinsic Functional Organization of the Human Brain. J. Cogn. Neurosci. 26, 501-513. doi:10.1162/jocn_a_00517

Cole, D.M., Smith, S.M., Beckmann, C.F., 2010. Advances and pitfalls in the analysis and interpretation of resting-state FMRI data. Front. Syst. Neurosci. 4, 8. doi:10.3389/fnsys.2010.00008

Cunningham, S.I., Weiland, J.D., Bao, P., Lopez-Jaime, G.R., Tjan, B.S., 2015. Correlation of vision loss with tactile-evoked V1 responses in retinitis pigmentosa. Vision Res. 111, 197-207. doi:10.1016/j.visres.2014.10.015

Di Pino, G., Pellegrino, G., Assenza, G., Capone, F., Ferreri, F., Formica, D., Ranieri, F., Tombini, M., Ziemann, U., Rothwell, J.C., Di Lazzaro, V., 2014. Modulation of brain plasticity in stroke: a novel model for neurorehabilitation. Nat. Publ. Gr. doi:10.1038/nrneurol.2014.162

Dosenbach, N.U.F., Fair, D. a, Miezin, F.M., Cohen, A.L., Wenger, K.K., Dosenbach, R.A.T., Fox, M.D., Snyder, A.Z., Vincent, J.L., Raichle, M.E., Schlaggar, B.L., Petersen, S.E., 2007. Distinct brain networks for adaptive and stable task control in humans. Proc. Natl. Acad. Sci. U. S. A. 104, 11073-8. doi:10.1073/pnas.0704320104

Doucet, G., Naveau, M., Petit, L., Delcroix, N., Zago, L., Crivello, F., Jobard, G., Tzourio-Mazoyer, N., Mazoyer, B., Mellet, E., Joliot, M., 2011. Brain activity at rest: a multiscale hierarchical functional organization. J. Neurophysiol. 105, 2753-63. doi:10.1152/jn.00895.2010

Eckert, M.A., Kamdar, N., Chang, C.E., Beckmann, C.F., Greicius, M.D., Menon, V., 2008. A crossmodal system linking primary auditory and visual cortices: Evidence from intrinsic fMRI connectivity analysis. Hum. Brain Mapp. 29, 848-857. doi:10.1002/hbm.20560

Engel, S., Rumelhart, D., Wandell, B., Lee, A., Glover, G., Chichilnisky, E., Shadlen, M., 1994. fMRI of human visual cortex. Nature 369, 525. doi:10.1038/369525a0

Falchier, A., Clavagnier, S., Barone, P., Kennedy, H., 2002. Anatomical evidence of multimodal integration in primate striate cortex. J. Neurosci. 22, 5749-59. doi:20026562

Forman, S.D., Cohen, J.D., Fitzgerald, M., Eddy, W.F., Mintun, M.A., Noll, D.C., 1995. Improved assessment of significant activation in functional magnetic resonance imaging (fMRI): use of a cluster-size threshold. Magn. Reson. Med. 33, 636-47.

Fox, M.D., Greicius, M., 2010. Clinical applications of resting state functional connectivity. Front. Syst. Neurosci. 4, 19. doi:10.3389/fnsys.2010.00019

Fox, M.D., Snyder, A.Z., Vincent, J.L., Corbetta, M., Van Essen, D.C., Raichle, M.E., 2005. The human brain is intrinsically organized into dynamic, anticorrelated functional networks. Proc. Natl. Acad. Sci. U. S. A. 102, 9673-8. doi:10.1073/pnas.0504136102

Friston, K.J., Holmes, A., Worsley, K.J., 1999. How many subjects constitute a study? Neuroimage 10, 1-5. doi:10.1006/nimg.1999.0439

Goebel, R., Esposito, F., Formisano, E., 2006. Analysis of functional image analysis contest (FIAC) data with brainvoyager QX: From single-subject to cortically aligned group general linear model analysis and self-organizing group independent component analysis. Hum. Brain Mapp. 27, 392401. doi:10.1002/hbm.20249

Golland, Y., Bentin, S., Gelbard, H., Benjamini, Y., Heller, R., Nir, Y., Hasson, U., Malach, R., 2007. Extrinsic and intrinsic systems in the posterior cortex of the human brain revealed during natural sensory stimulation. Cereb. Cortex 17, 766-77. doi:10.1093/cercor/bhk030

Golland, Y., Golland, P., Bentin, S., Malach, R., 2008. Data-driven clustering reveals a fundamental 
subdivision of the human cortex into two global systems. Neuropsychologia 46, 540-53. doi:10.1016/j.neuropsychologia.2007.10.003

Greicius, M.D., Krasnow, B., Reiss, A.L., Menon, V., 2003. Functional connectivity in the resting brain: a network analysis of the default mode hypothesis. Proc. Natl. Acad. Sci. U. S. A. 100, 253-8. doi:10.1073/pnas.0135058100

Guerra-Carrillo, B., Mackey, A.P., Bunge, S.A., 2014. Resting-State fMRI: A Window into Human Brain Plasticity. Neurosci. 20, 522-533. doi:10.1177/1073858414524442

Hagoort, P., 2005. On Broca, brain, and binding: a new framework. Trends Cogn. Sci. 9, 416-23. doi:10.1016/j.tics.2005.07.004

Hampson, M., Peterson, B.S., Skudlarski, P., Gatenby, J.C., Gore, J.C., 2002. Detection of functional connectivity using temporal correlations in MR images. Hum. Brain Mapp. 15, 247-62. doi:10.1002/hbm.10022

Heine, L., Bahri, M. A., Cavaliere, C., Soddu, A., Laureys, S., Ptito, M., Kupers, R., 2015. Prevalence of increases in functional connectivity in visual, somatosensory and language areas in congenital blindness. Front. Neuroanat. 9. doi:10.3389/fnana.2015.00086

Hertz, U., Amedi, A., 2010. Disentangling unisensory and multisensory components in audiovisual integration using a novel multifrequency fMRI spectral analysis. Neuroimage 52, 617-32. doi:10.1016/j.neuroimage.2010.04.186

Hodge, M.R., Horton, W., Brown, T., Herrick, R., Olsen, T., Hileman, M.E., McKay, M., Archie, K. a., Cler, E., Harms, M.P., Burgess, G.C., Glasser, M.F., Elam, J.S., Curtiss, S.W., Barch, D.M., Oostenveld, R., Larson-Prior, L.J., Ugurbil, K., Van Essen, D.C., Marcus, D.S., 2015. ConnectomeDB - Sharing human brain connectivity data. Neuroimage. doi:10.1016/j.neuroimage.2015.04.046

Johnson, M.D., Ojemann, G.A., 2000. The role of the human thalamus in language and memory: evidence from electrophysiological studies. Brain Cogn. 42, 218-30. doi:10.1006/brcg.1999.1101

Kalloniatis, M., Fletcher, E.L., 2004. Retinitis pigmentosa: understanding the clinical presentation, mechanisms and treatment options. Clin. Exp. Optom. 87, 65-80.

Heckenlively J.T.R, "Good days, bad days", in Retinitis Pigmentosa, Philadelphia, Lippincott, 1988, p 73.

Lee, D.S., Lee, J.S., Oh, S.H., Kim, S.K., Kim, J.W., Chung, J.K., Lee, M.C., Kim, C.S., 2001. Crossmodal plasticity and cochlear implants. Nature 409, 149-50. doi:10.1038/35051653

Li, J., Liu, Y., Qin, W., Jiang, J., Qiu, Z., Xu, J., Yu, C., Jiang, T., 2013. Age of onset of blindness affects brain anatomical networks constructed using diffusion tensor tractography. Cereb. Cortex 23, 542-51. doi:10.1093/cercor/bhs034

Liu, Y., Yu, C., Liang, M., Li, J., Tian, L., Zhou, Y., Qin, W., Li, K., Jiang, T., 2007. Whole brain functional connectivity in the early blind. Brain 130, 2085-96. doi:10.1093/brain/awm121

Logothetis, N.K., Murayama, Y., Augath, M., Steffen, T., Werner, J., Oeltermann, A., 2009. How not to study spontaneous activity. Neuroimage $45,1080-1089$.

doi:10.1016/j.neuroimage.2009.01.010

Masuda, Y., Horiguchi, H., Dumoulin, S.O., Furuta, A., Miyauchi, S., Nakadomari, S., Wandell, B.A., 2010. Task-dependent V1 responses in human retinitis pigmentosa. Invest. Ophthalmol. Vis. Sci. 51, 5356-64. doi:10.1167/iovs.09-4775

Murphy, K., Birn, R.M., Handwerker, D.A., Jones, T.B., Bandettini, P.A., 2009. The impact of global 
signal regression on resting state correlations: Are anti-correlated networks introduced? Neuroimage 44, 893-905. doi:10.1016/j.neuroimage.2008.09.036

Noppeney, U., Friston, K.J., Price, C.J., 2003. Effects of visual deprivation on the organization of the semantic system. Brain 126, 1620-7. doi:10.1093/brain/awg152

Pascual-Leone, A., Amedi, A., Fregni, F., Merabet, L.B., 2005. The plastic human brain cortex. Annu. Rev. Neurosci. 28, 377-401. doi:10.1146/annurev.neuro.27.070203.144216

Pessoa, L., and De Weerd, P. (Eds.). (2003). Filling-in: From perceptual completion to cortical reorganization. Oxford University Press. Chapter 5 Page 98

Price, C.J., 2010. The anatomy of language: a review of $100 \mathrm{fMRI}$ studies published in 2009. Ann. N. Y. Acad. Sci. 1191, 62-88. doi:10.1111/j.1749-6632.2010.05444.x

Raz, N., Amedi, A., Zohary, E., 2005. V1 activation in congenitally blind humans is associated with episodic retrieval. Cereb. Cortex 15, 1459-68. doi:10.1093/cercor/bhi026

Raichle, M.E., MacLeod, a M., Snyder, a Z., Powers, W.J., Gusnard, D. a, Shulman, G.L., 2001. A default mode of brain function. Proc. Natl. Acad. Sci. U. S. A. 98, 676-82. doi:10.1073/pnas.98.2.676

Reislev, N.L., Dyrby, T.B., Siebner, H.R., Kupers, R., Ptito, M., 2016. Simultaneous Assessment of White Matter Changes in Microstructure and Connectedness in the Blind Brain. Neural Plast. 2016, 6029241. doi:10.1155/2016/6029241

Sadato, N., Okada, T., Honda, M., Yonekura, Y., 2002. Critical period for cross-modal plasticity in blind humans: a functional MRI study. Neuroimage 16, 389-400. doi:10.1006/nimg.2002.1111

Särkämö, T., Tervaniemi, M., Laitinen, S., Forsblom, A., Soinila, S., Mikkonen, M., Autti, T., Silvennoinen, H.M., Erkkilä, J., Laine, M., Peretz, I., Hietanen, M., 2008. Music listening enhances cognitive recovery and mood after middle cerebral artery stroke. Brain 131, 866-876. doi:10.1093/brain/awn013

Sarubbo, S., De Benedictis, A., Maldonado, I.L., Basso, G., Duffau, H., 2013. Frontal terminations for the inferior fronto-occipital fascicle: Anatomical dissection, DTI study and functional considerations on a multi-component bundle. Brain Struct. Funct. 218, 21-37. doi:10.1007/s00429-011-0372-3

Sereno, M.I., Dale, a M., Reppas, J.B., Kwong, K.K., Belliveau, J.W., Brady, T.J., Rosen, B.R., Tootell, R.B., 1995. Borders of multiple visual areas in humans revealed by functional magnetic resonance imaging. Science 268, 889-93.

Shmuel, A., Augath, M., Oeltermann, A., Logothetis, N.K., 2006. Negative functional MRI response correlates with decreases in neuronal activity in monkey visual area V1. Nat. Neurosci. 9, 569577. doi:10.1038/nn1675

Shmuel, A., Yacoub, E., Pfeuffer, J., Van de Moortele, P.-F., Adriany, G., Hu, X., Ugurbil, K., 2002. Sustained Negative BOLD, Blood Flow and Oxygen Consumption Response and Its Coupling to the Positive Response in the Human Brain. Neuron 36, 1195-1210. doi:10.1016/S08966273(02)01061-9

Shu, N., Liu, Y., Li, J., Li, Y., Yu, C., Jiang, T., 2009. Altered anatomical network in early blindness revealed by diffusion tensor tractography. PLoS One 4, 1-13. doi:10.1371/journal.pone.0007228

Shulman, G.L., Fiez, J. a., Corbetta, M., Buckner, R.L., Miezin, F.M., Raichle, M.E., Petersen, S.E., 1997. Common Blood Flow Changes across Visual Tasks: II. Decreases in Cerebral Cortex. J. Cogn. Neurosci. 9, 648-663. doi:10.1162/jocn.1997.9.5.648

Smith, S.M., Fox, P.T., Miller, K.L., Glahn, D.C., Fox, P.M., Mackay, C.E., Filippini, N., Watkins, K.E., Toro, R., Laird, A.R., Beckmann, C.F., 2009. Correspondence of the brain's functional 
architecture during activation and rest. Proc. Natl. Acad. Sci. U. S. A. 106, 13040-5. doi:10.1073/pnas.0905267106

Spreng, R.N., Stevens, W.D., Chamberlain, J.P., Gilmore, A.W., Schacter, D.L., 2010. Default network activity, coupled with the frontoparietal control network, supports goal-directed cognition. Neuroimage 53, 303-17. doi:10.1016/j.neuroimage.2010.06.016

Stingl, K., Bartz-Schmidt, K.U., Besch, D., Braun, A., Bruckmann, A., Gekeler, F., Greppmaier, U., Hipp, S., Hörtdörfer, G., Kernstock, C., Koitschev, A., Kusnyerik, A., Sachs, H., Schatz, A., Stingl, K.T., Peters, T., Wilhelm, B., Zrenner, E., 2013. Artificial vision with wirelessly powered subretinal electronic implant alpha-IMS. Proc. Biol. Sci. 280, 20130077. doi:10.1098/rspb.2013.0077

Striem-Amit, E., Bubic, A., Amedi, A., 2011a. Mechanisms Underlying Plastic Changes and Rehabilitation following Sensory Loss in Blindness and Deafness, in: The Neural Bases of Multisensory Processes. pp. 395-422.

Striem-Amit, E., Hertz, U., Amedi, A., 2011b. Extensive cochleotopic mapping of human auditory cortical fields obtained with phase-encoding FMRI. PLoS One 6, e17832. doi:10.1371/journal.pone.0017832

Striem-Amit, E., Ovadia-Caro, S., Caramazza, A., Margulies, D.S., Villringer, A., Amedi, A., 2015. Functional connectivity of visual cortex in the blind follows retinotopic organization principles. Brain 138, 1679-1695. doi:10.1093/brain/awv083

Sundermann, B., Pfleiderer, B., 2012. Functional connectivity profile of the human inferior frontal junction: involvement in a cognitive control network. BMC Neurosci. 13, 119. doi:10.1186/1471-2202-13-119

Tagliazucchi, E., Wegner, F. Von, Morzelewski, A., Brodbeck, V., Laufs, H., von Wegner, F., Morzelewski, A., Brodbeck, V., Laufs, H., 2012. Dynamic BOLD functional connectivity in humans and its electrophysiological correlates. Front. Hum. Neurosci. 6, 339. doi:10.3389/fnhum.2012.00339

Talairach, J., Tournoux, P., 1988. Co-planar stereotaxic atlas of the human brain. 3-Dimensional proportional system: an approach to cerebral imaging. Thieme, New York.

van Dijk, K.R.A., Sabuncu, M.R., Buckner, R.L., 2012. The influence of head motion on intrinsic functional connectivity MRI. Neuroimage 59, 431-438. doi:10.1016/j.neuroimage.2011.07.044

Vincent, J.L., Kahn, I., Snyder, A.Z., Raichle, M.E., Buckner, R.L., 2008. Evidence for a frontoparietal control system revealed by intrinsic functional connectivity. J. Neurophysiol. 100, 3328-42. doi:10.1152/jn.90355.2008

Wandell, B. A, Dumoulin, S.O., Brewer, A. a, 2007. Visual field maps in human cortex. Neuron 56, 366-83. doi:10.1016/j.neuron.2007.10.012

Wandell, B.A., Smirnakis, S.M., 2009. Plasticity and stability of visual field maps in adult primary visual cortex. Nat. Rev. Neurosci. 10, 873-84. doi:10.1038/nrn2741

Wandell, B.A., Winawer, J., 2011. Imaging retinotopic maps in the human brain. Vision Res. 51, 71837. doi:10.1016/j.visres.2010.08.004

Watkins, K.E., Cowey, A., Alexander, I., Filippini, N., Kennedy, J.M., Smith, S.M., Ragge, N., Bridge, H., 2012. Language networks in anophthalmia: maintained hierarchy of processing in "visual" cortex. Brain 135, 1566-77. doi:10.1093/brain/aws067

Weiland, J.D., Humayun, M.S., 2014. Retinal prosthesis. IEEE Trans. Biomed. Eng. 61, 1412-24. doi:10.1109/TBME.2014.2314733

Whitfield-Gabrieli, S., Ford, J.M., 2012. Default mode network activity and connectivity in 
psychopathology. Annu. Rev. Clin. Psychol. 8, 49-76. doi:10.1146/annurev-clinpsy-032511143049

Yetkin, F.Z., Hammeke, T.A., Swanson, S.J., Morris, G.L., Mueller, W.M., McAuliffe, T.L., Haughton, V.M., 1995. A comparison of functional MR activation patterns during silent and audible language tasks. AJNR. Am. J. Neuroradiol. 16, 1087-92.

Zeharia, N., Hertz, U., Flash, T., Amedi, A., 2012. Negative blood oxygenation level dependent homunculus and somatotopic information in primary motor cortex and supplementary motor area. Proc. Natl. Acad. Sci. 109, 18565-18570. doi:10.1073/pnas.1119125109 


\section{Within-group FC analysis seeded from Broca's area (calcarine sulcus/cuneus)}

A. Sighted control

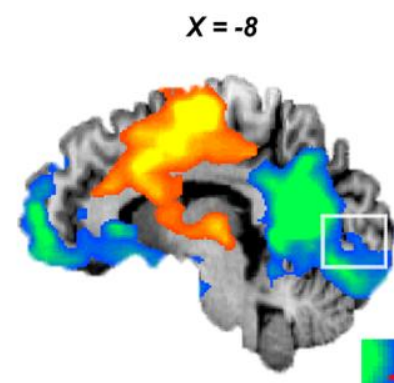

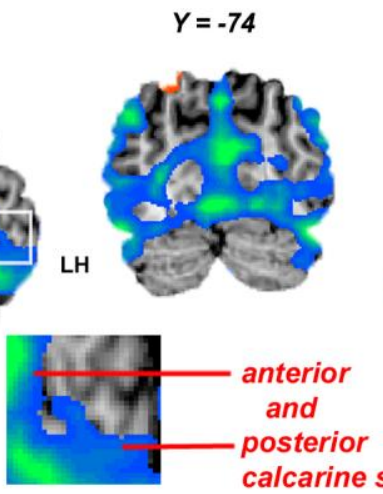

calcarine sulcus / cuneus

LH: Left hemisphere RH: Right hemisphere

B. RP tunnel vision
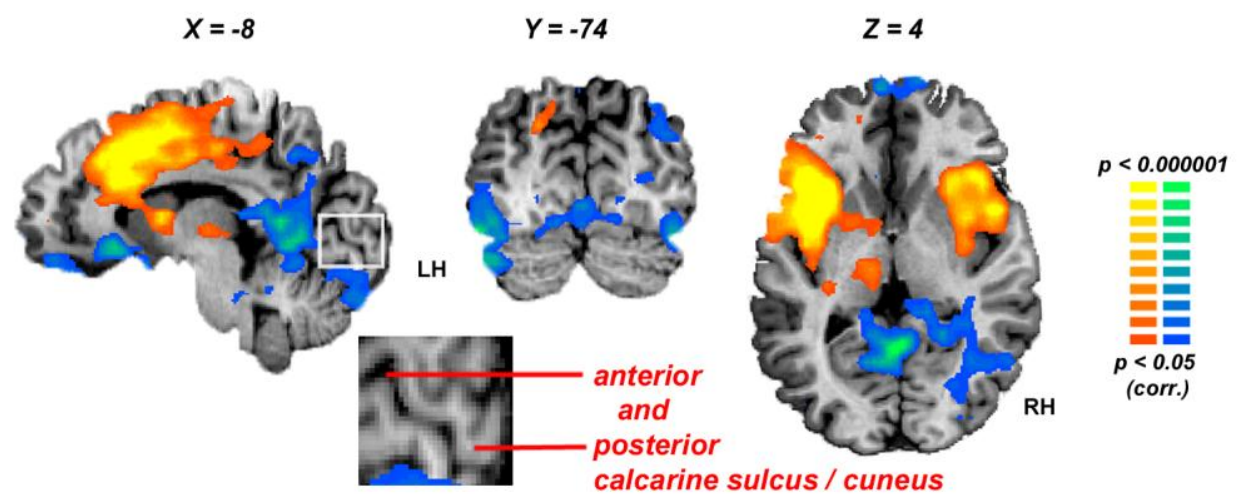

C. RP blind
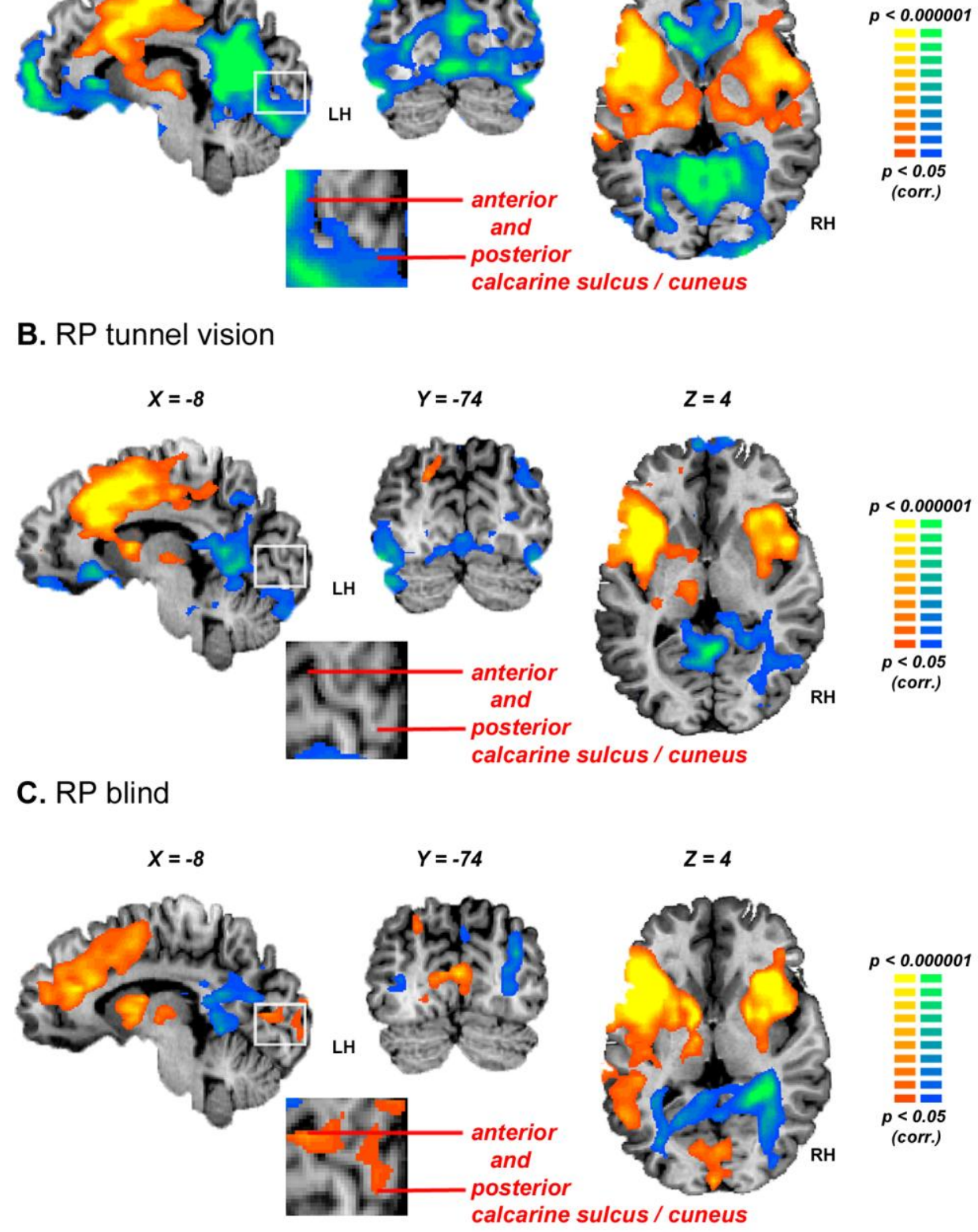

(corr.)

Figure 1 


\section{Between-groups $\mathrm{FC}$ analysis seeded from Broca's area (calcarine sulcus/cuneus)}

A. RP blind vs. Sighted control

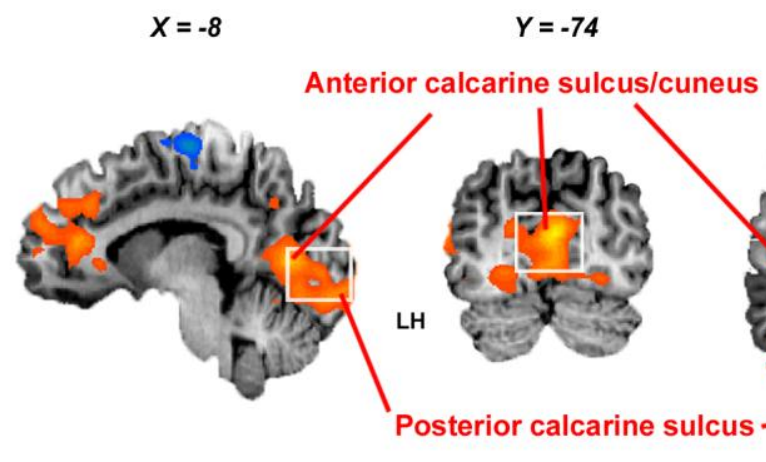

Within-group:

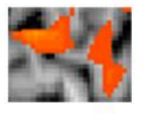

B

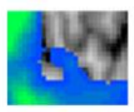

S

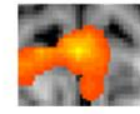

B

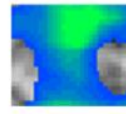

S
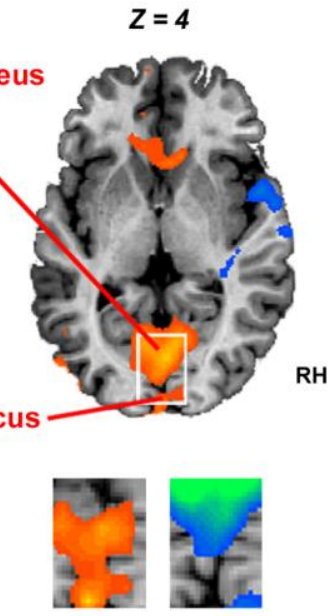

B S

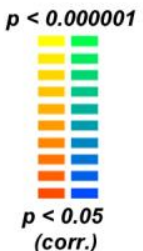

B. RP tunnel vision vs. Sighted control

B: RP blind

TV: RP tunnel vision

S: Sighted control

$X=-8$

$Y=-74$

LH: Left hemisphere LH: Left hemisphere
RH: Right hemisphere

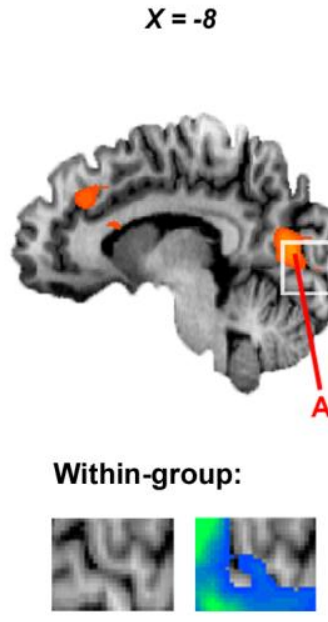

TV

S

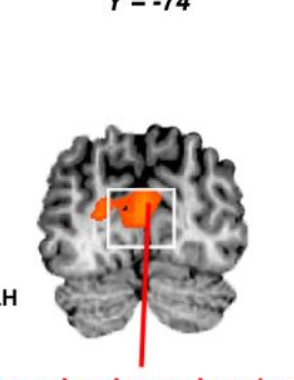

Anterior
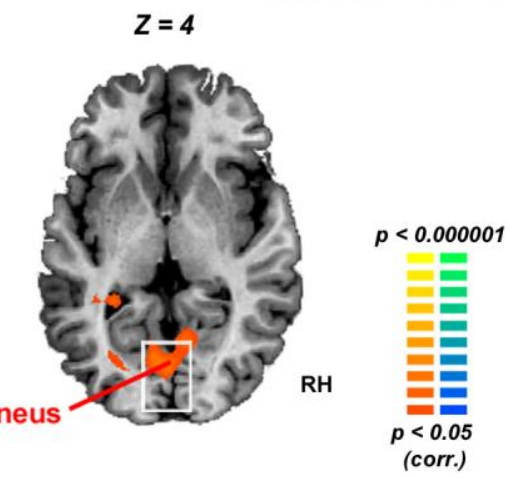

Figure 2

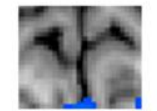

TV

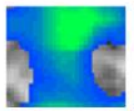

S

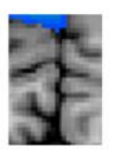

TV S 


\section{Between-groups FC analysis seeded from Broca's area (extrastriate areas)}

A. RP blind vs. Sighted control
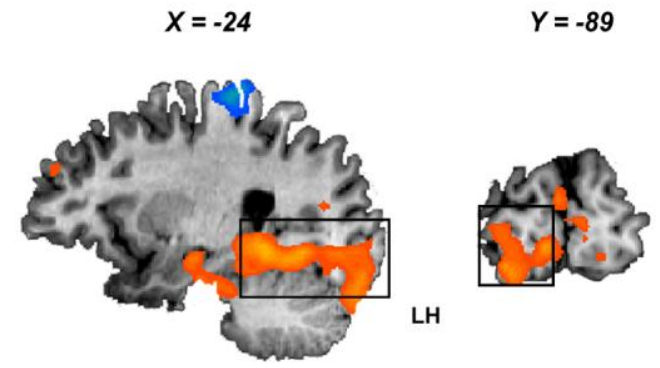

Within-group:

B

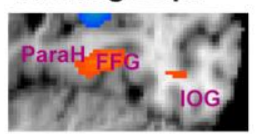

S

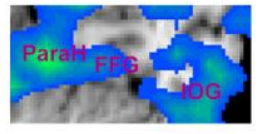

B. RP blind vs. RP tunnel vision

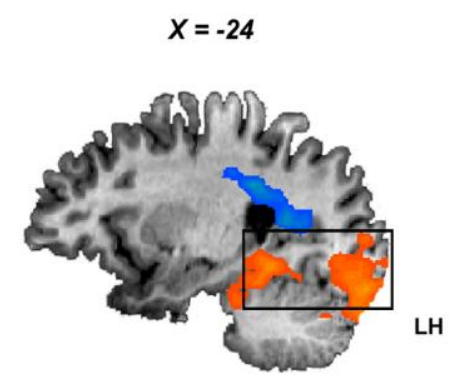

Within-group:

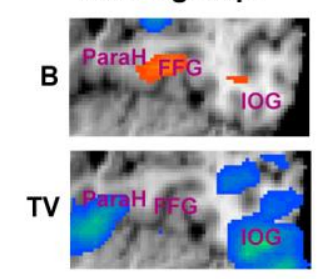

$Y=-89$

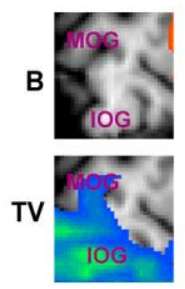

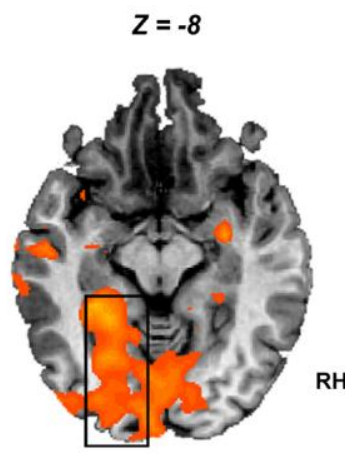

$p<0.000001$

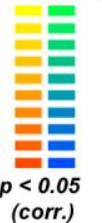

B

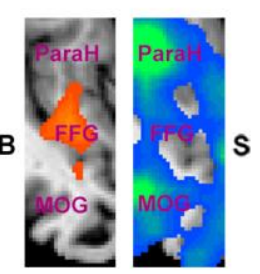

B: RP blind

TV: RP tunnel vision

S: Sighted control
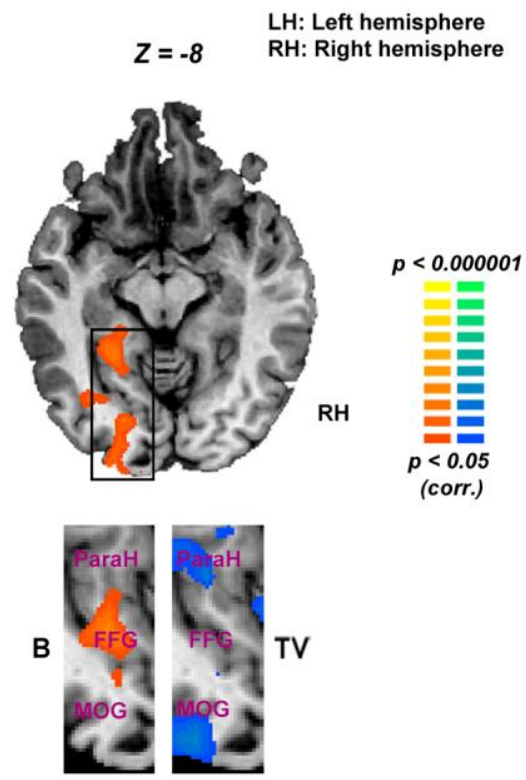

Figure 3 
Left posterior calcarine sulcus and Broca's area

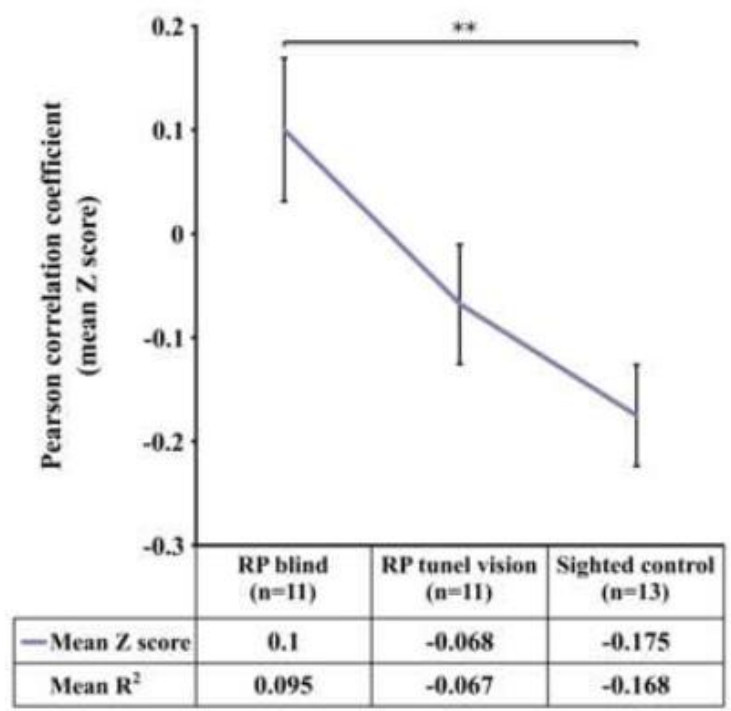

Left anterior calcarine sulcus and Broca's area

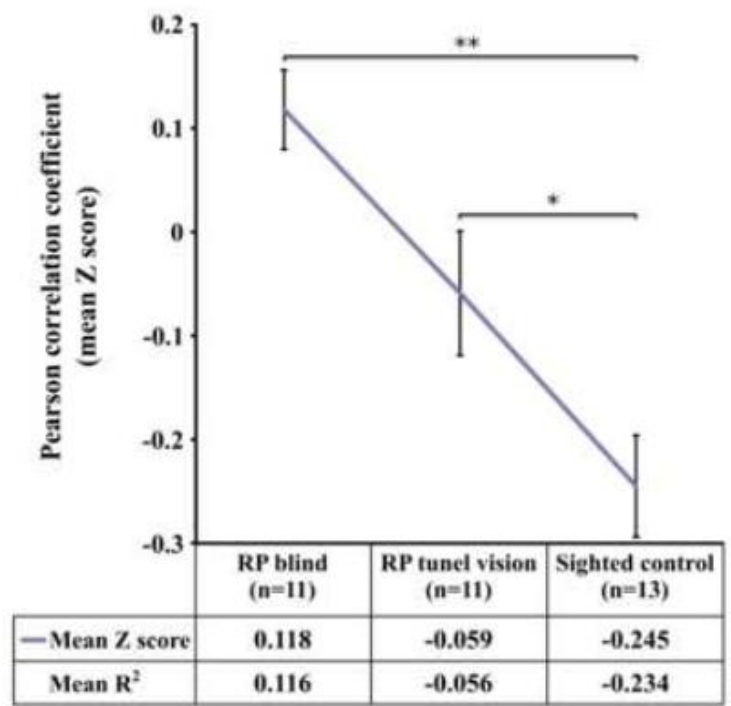

Figure 4 